\title{
Augmented Reality APPs Applied in Intelligent Crafts Using Project- Based and Collaborative Learning
}

\author{
Cheng-Min Lin ${ }^{+}$, Chiu-Chiao Chung and Tzu-Chi Lin \\ Department of Digital Living Innovation, Nan Kai University of Technology, No. 568, Zhongzheng Rd., \\ Nantao, Caotun 542, Taiwan (R.O.C.)
}

\begin{abstract}
A project-based learning course for college students are applied in designing and implementing for intelligent crafts with Augmented Reality APPs. To encourage the learning motivation, some festival activities are designed through the project-based learning to create more values of celebration, for examples, the Mother's Day and Chinese Valentine's Day. Students progressed significantly and accumulated valuable experiences especially when they worked together with local artists or technologists using collaborative learning, since teaching and learning promote and enhance each other. The project-based and collaborative learning are implemented through the project of "Reforming tea factory in Lugu Township into a Smart Living Lab", which is a successful study case provided by the Ministry of Education in Taiwan. The smart living technologies, such as Augmented Reality (AR), and mobile applications (APPs), were introduced to those local artists then they conducted local festival activities to promote their township journeys.
\end{abstract}

Keywords: augmented reality, intelligent living technology, project-based learning, collaborative learning, and APPs.

\section{Introduction}

The learning strategy for the project-based or collaborative learning is one of instructional strategies to provide students to engage with other students resulting in a deeper understanding and higher motivation [1]. There are two types of guiding strategy (procedure-guided vs. question-guided) employed in 152 freshmen of senior high school in Taiwan [2]. The study shows that the learner' average scores of the procedure-guided strategy were better than that of question-guided strategy in terms of knowledge application. This research also takes into account the learning strategy with Augmented Reality (AR) applications by using smart phones in classroom, the results shows that the learner' average scores based on static-AR is better than that of dynamic-AR in electrical or chemical concept, constantly. It depends on what education software installed on the phone for them to use. Reports about software applications of smart phone in Macquarie's University, Sydney Australia, the project of AR is used to support the development of students' higher order thinking capabilities [3]. There were 16 high school students ranging in level from grade 8 to 10 , invited to participate in their project aimed at exploring the potential of AR in schools. Researches show that AR technology improves both teaching and learning experiences, and brings interactive dimension into the whole picture [4].

The project-based learning and collaborative learning are implemented in this study through the project of "Reforming tea factory in Lugu Township into a Smart Living Lab", which is a successful study case provided by the Ministry of Education in Taiwan. Students progressed significantly and accumulated valuable experiences especially when they worked together with local artists or technologists, because of teaching and learning promote and enhance each other.

During the process of cooperation, students work in team together with local artists. Some intelligent crafts, including Bamboo QR Code, Pattern flower AR, and URSA Light were produced [5]. Especially, the

\footnotetext{
Corresponding author. Tel.: +886-49-2563489\#2931; fax: +886-49-2561757.

E-mail address: 1cm@nkut.edu.tw.
} 
Augmented Reality was well developed to present the topics of festival activities, so that those local artists conducted their local activities to promote the township journeys.

\section{Flower AR for Mother's day}

The proposed project-based learning for students is to design greeting cards with pattern flowers for Mother's day. Students are encouraged to present their love to mothers by showing their creativity and designing skills on the AR developments. Local artists are invited and join the team works to guide students how to design greeting cards with Pattern flowers. A series of design works for Mother's day are introduced in the following sections.

\subsection{Static 3D on AR}

The first AR cards by using Pattern flowers were co-designed with local artists in 2013. A marker-based AR tool called AndAR was used to enable Augmented Reality on Android platforms. To run the project, the artists should know what the AR technology is and how to design a marker using Pattern flower. It is difficult for artists to design a good pattern as an AR marker, since they do not have the sense of marker with some pattern of Pattern flower. It takes times; those markers can successfully be identified by AR application software (APPs) after the artists learned. The marker by using a leaf was designed as shown in Figure 1.

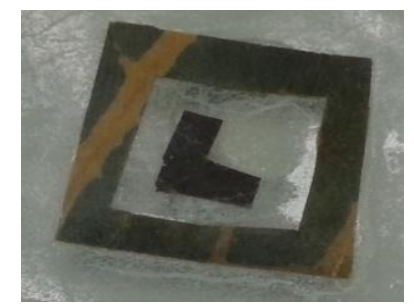

Fig. 1: A marker is designed by using a leaf.

This AR application for project is called Bee-And-Butterfly. Since the material of Pattern flower is made from plant, a bee and a butterfly are designed as 3D objects to meet the topic while these markers are detected. The open-source codes bring benefits for students' learning. Due to different versions of open source, students met a great sense of frustration when they try to execute these projects. For example, there was a mistake due to different versions of android as the source code of ModelChooser developed by AndAR, and it could be revised by changing "the lib directory" into "the libs directory"[6]. Although this work is easy, it is hard for beginners.

Courses of 3D modeling, AR marker, and AR application are provided for project-based learning. The 3D model is developed by 3D software, such as Blender (https://www.blender.org/). It needs to pay attention to the AndAR integrating with 3D object created by Blender [7]. When an output file is generated, five parameters can be selected, including Write Normals, Write Materials, Taiangulate Faces, Material Group, and Keep Vertex Order. The AndAR output file format "mtl" and "obj" is created by the online AR marker generator [8], with the marker was blocked. Figure 2 demonstrates the architecture of this project. The architecture consists of a server and a client APPs. The server provides the APPs download for users. A welcome screen and two buttons are provided for user selection in the client's APPs. One button shows menu for presenting how to operate the APPs, another is to demonstrate the function of AR. The AR application is developed by Andriod using the Eclipse tool.

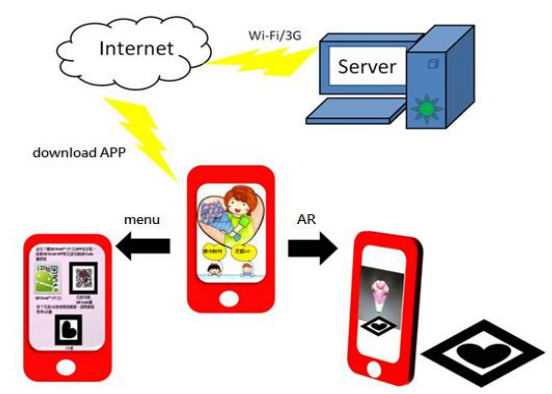

Fig. 2: The architecture of proposed project. 


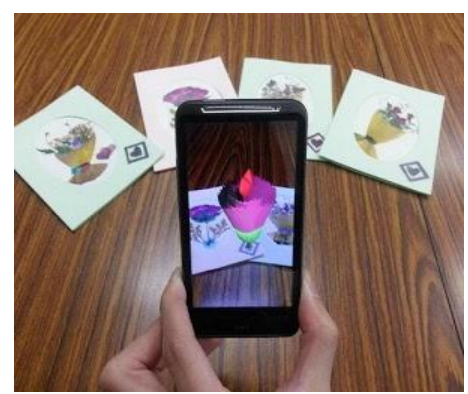

Fig. 3: The 3D pattern of Carnation is shown over AR marker designed by Pattern flower in 2013.

\subsection{Video Playback on AR}

The next, different technologies were applied to Pattern flower Mother's Card, with markerless-based and video playback instead of maker-based and 3D static objects. In artists' opinion, AR markers designed by Pattern flower doesn't match with their Pattern flower works. Therefore, the development toolkit was changed from AndAR to Vuforia. The Vuforia SDK is the industry AR platform, which natural features and image ratings are used in makerless-based AR. The feature means a "corner" of a shape, there are no features for a circle, but four features for a square. A target manager is used to manage image objects. The image ratings are used in the manager to help users to identify good features in the image object. Table 1 illustrates image ratings for three pictures designed by pattern flowers. The Owl pattern flower gets one star rating, and the House one gets five star rating. It would be easier for students and artists to use image processing techniques to identify different real objects, and design pattern flower works have five-star rating.

Table 1: Star Rating in the Features of Three Pattern Flowers

\begin{tabular}{llll} 
Name & Picture & Features & Star Rating \\
\hline Owl & & & \\
House & & \\
Flower & &
\end{tabular}

Video clips instead of 3D objects were used due to it is easier to create than 3D objects. The re-designed Mother's Card with video playback technology in 2014 is shown in Fig. 4, without any makers in the pattern flower card.

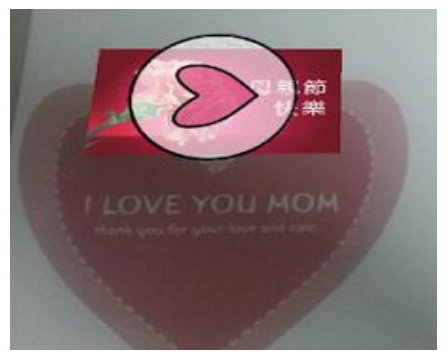

Fig. 4: Using video playback technology designs the pattern flower card APPs for Mother's Day in 2014.

Although the video playback for students is easy to implement and the method is quite charming, the video file size is too large. Storing the video files on a cloud server and encapsulating those in the APPs are good matters for teaching students the concept of limitation of executable file size and network transmission.

\subsection{D Animations on AR}

The animation courses are further trained in the third year for make more surprises and interests. The Android eclipse SDK may be used to design 3D animation. Although 3D Animation is very attractive, it is difficult to learn for students are not major in information engineering. To exploit the learning strategy, the development toolkit was changed again by selecting Unity instead of Android eclipse SDK. The Unity is the game engine toolkit, and has a powerful support in 3D animation. In addition, Vuforia SDK also provides 
Unity to support AR function. The advanced design of Mother's Card released in 2015 is shown in Figure 5, with plants growing up and three puppies following by their mother.

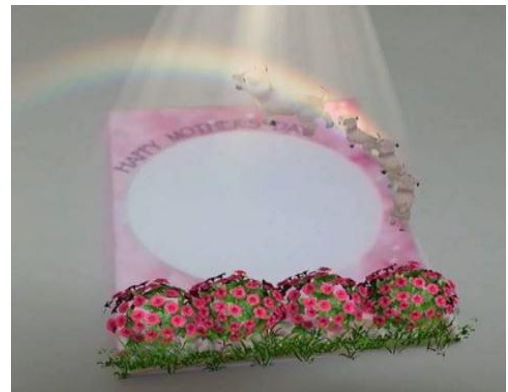

Fig. 5: The Pattern flower Mother's card APPs designed by 3D animation in 2015.

\section{Flower AR for Chinese Valentine's day}

Students are encouraged to get through with more trainings and exercises by teamwork, or microentrepreneur. The advanced project was assigned to prepare the Chinese Valentine's Day Activities at the tea factory located in Chuxiang Village, Lugu Township, Nantou County, Taiwan.

In this activity, six subjects are planned, including hand-making Pattern flower card, fabricating love movie, cooking tea lunch, arranging flowers, serving tea, and running APPs for Chinese Valentine's Day. Video playback technology was developed for the AR APPs. The picture on Chinese Valentine's card can be converted into pattern of video playback by using the APPs, as illustrated in Table 2. The APPs can also be free downloaded from the website https://play.google.com/store/apps/details?id=nkut.cce.vv5\&hl=zh-TW. Since the design method has confidentiality, specificity and uniqueness, the application must use a specific card to play videos.

Table 2: Flower AR for Chinese Valentine's Day

\begin{tabular}{lll}
\hline \hline Before Identification & After Identification \\
\hline & & \\
\hline
\end{tabular}

Furthermore, in order to challenge the more difficult task, identifying the AR objects from a flat into a cylinder has been designed. It encounters some problems while tea canister cover with Pattern flower and the AR technology implemented, such as: cylindrical shaped image tags, data base for image tags, and mobile applications. The tea canister cover with Pattern flower was designed through AR technologies to realize interdisciplinary products. Figure 6 shows the embedded AR technology in Tea-Canister Cover with Pattern flower, a design based on smart living technologies with cultural and creative thoughts.

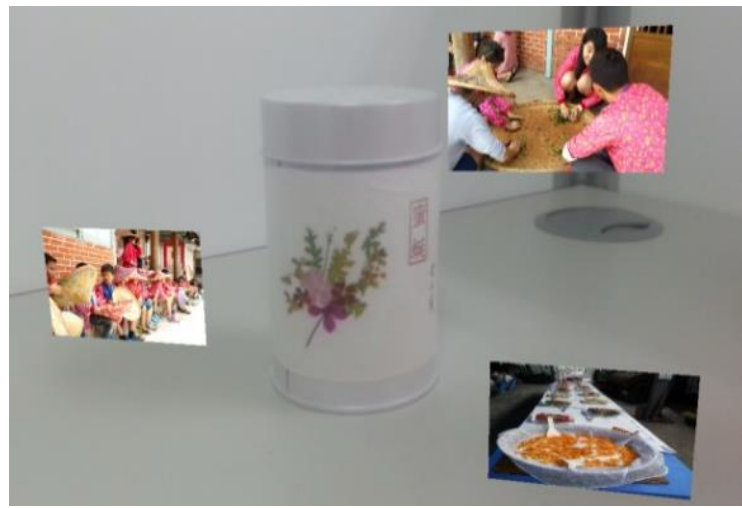

Fig. 6: Embed AR technology in Tea-Canister Cover with Pattern flower. 


\section{Discussions}

To encourage the learning motivation, the Mother's Day activities are designed through the projectbased learning to create more values of celebration. Through three-year co-work opportunities, students learn to work with artists and design intelligent crafts by using AR technology. They participated in the projectbased courses and experienced three different design patterns, including 3D static object, video playback, and 3D animations. Beside the design skills, they also implement the business model for their design works. Students are really rewarded lots from the project-oriented learning strategies.

Two learning strategies are discussed in this work. One is project-based learning is used to develop a team spirit together to solve problems and the other is to cooperate with local artists to design an innovation products as illustrated in Table 3. Project-based learning has an advantage of clear objectives, i.e. task target and how to work on it, but it is unpredictable. It also depends on the membership, capability and timing control. However, collaborative learning emphasizes cooperation with others. The expertise interdisciplinary approaches were used in this work. Students with background science and technology cooperated with artists.

Table 3: Comparison of Project-Based and Collaborative Learning

\begin{tabular}{cccc}
\hline \hline Name & Purpose & Advantage & Disadvantage \\
\hline Project-based Learning & Team spirit & Clear objectives & Unpredictable \\
Collaborative Learning & Work with local artists & Interdisciplinary cooperation & Artists need to cooperate \\
\hline \hline
\end{tabular}

According to our research, the technology of pattern flower is suitable for a marker or a target for AR APPs. In this study, we discuss three ways to design flower AR, including Static 3D, Video Playback, and Animation. Table 4 illustrates advantage and disadvantage of three methods. The static 3D method has clear targets due to use marker-based AR. According to researches, the performance of APPs designed by AndAR is worse than that designed by Vuforia, and the Video Playback method is easy to implement. The development time is shorter but the Animation method has attractive for user experiences.

Table 4: Comparison of Three Methods of Flower AR

\begin{tabular}{cccc}
\hline \hline Name & Toolkits & Advantage & Disadvantage \\
\hline Static 3D & AndAR, Android SDK, Eclipse & Clear Targets & Unstable \\
Video Playback & Vuforia, Eclipse, Android SDK, & Stable, Easy to implement & Unclear Tagets \\
Animation & Vuforia, Android SDK, Unity & Stable, Attractive & Unclear Tagets \\
\hline \hline
\end{tabular}

In this work, we proposed two innovation festival activities using the flower AR of smart intelligent technologies, including Mother's Day and Chinese Valentine's Day as illustrated in Table 5. Two different ways including works and journey are used in Mother's Day and Chinese Valentine's Day, respectively. In Mother's Day, an innovation card with a free AR APPs as a product is designed. In Chinese Valentine's Day, a journey was arranged to receipt couples for the unforgettable holiday.

Table 5: Comparison of Two Activities of Project-Based Learning

\begin{tabular}{cccc}
\hline \hline Name & Way & Advantage & Disadvantage \\
\hline Flower AR for Mother's Day & Works & More products to sell & Lack of scene sense \\
Flower AR for Chinese Valentine's Day & Journey & Field experience & High labor cost \\
\hline \hline
\end{tabular}

\section{Conclusions}

In this work, the project-based learning strategy was introduced. The project-based strategy has been running for three years, students from freshman to junior. While they participated in this learning strategy, students progressed significantly and accumulated valuable experiences especially when they worked together with local artists or technologists, since teaching and learning promote and enhance each other. Collaborative learning strategy has complementary for students and local artists. In science and technology applications, students are better than artists. On the contrary, the local artists have better aesthetic quality.

The use of Augmented Reality technology will be continued studying to achieve the integration of virtual and physical applications in the future. It would be focused on the features of natural materials and 3D 
objects action script by using mark-up language.

\section{Acknowledgements}

The authors would like to thank the National Science Council of the Republic of China, Taiwan for financially supporting this research under Contract No. MOST 104-2221-E-252-006 -. The excellent comments of the anonymous reviewers are greatly acknowledged that have helped a lot in improving the quality and readability of the paper.

\section{References}

[1] D. N. E. Phone, M. B. Ali, and N. D. A. Halim. Collaborative augmented reality in education: a review. In 2014 International Conference on Teaching and Learning in Computing and Engineering, 2014.

[2] M. P. Chen. Augmented reality laboratory for high school electrochemistry course. In 2015 IEEE 15th International Conference on Advanced Learning Technologies, 2015.

[3] M. Brower. 2013. Augmented reality in education - cases, places, and potentials. In 2013 IEEE 63rd Annual Conference International Council for Educational Media (ICEM), 2013.

[4] B. Kraut, and J. Jeknić. Improving education experience with augmented reality (AR). In MIPRO 2015, Opatija, Croatia, May 2015, pp.25-29.

[5] T. C. Lin, C. M. Lin, C. W. Lin. The design and implementation of the intelligent crafts for digital arts. In International Computer Symposium (ICS 2014), Taichung, Taiwan, Dec. 12-14 2014.

[6] http://cheng-min-i-taiwan.blogspot.tw/2013/01/android-ar-andarmodelchooser.html.

[7] http://cheng-min-i-taiwan.blogspot.tw/2014/04/android-blender-blender-3d-andar.html.

[8] http://flash.tarotaro.org/blog/2008/12/14/artoolkit-marker-generator-online-released/ 